\title{
ULTRASOUND AND MAGNETIC RESONANCE ENTEROGRAPHY IN DIAGNOSIS OF CROHN'S DISEASE IN CHILDREN
}

\section{ULTRAZVUK I MAGNETNO REZONANTNA ENTEROGRAFIJA U DIJAGNOSTICI KRONOVE BOLESTI U DEČJEM UZRASTU}

\author{
Sofija Cvejić ${ }^{1}$, Sara Filipović ${ }^{1}$, Polina Pavićevićc ${ }^{1,2}$, Vojkan Vukadinović $c^{1,2}$ \\ ${ }^{1}$ Univerzitet u Beogradu, Medicinski fakultet, Beograd, Srbija \\ ${ }^{2}$ Univerzitetska dečja klinika Tiršova, Beograd, Srbija
}

Correspondence: sofija.cvejic@yahoo.com

Abstract

Introduction: Crohn's disease is a chronic inflammatory bowel disease, which is characterized by remitting and relapsing episodes, and commonly affects younger than 30. Magnetic resonance enterography (MRE) and ultrasound (US) are taking the leading role over colonoscopy and computed tomography (CT) in diagnostics, initial estimation of Crohn's disease and monitoring of activity, detection and evaluation of complications.

Aim: To examine sensitivity (SE), specificity (SP), positive predictive value (PPV), negative predictive value (NPV) of US and MRE in diagnosis of Crohn's disease. Also, to examine overall diagnostic value of MRE comparing morphological and functional parameters with endoscopic findings.

Material and methods: 40 patients were observed from the end of year 2009 to the end of 2016. Diagnosed patients with clinical and laboratory findings were sent for US and MRE examination. US evaluated wall thickness, mesenteric fibrofatty proliferation and enlargement of mesenteric lymph nodes. Beside this, MRE also evaluated bowel wall enhancement and layered enhancement pattern.

Results: Overall diagnostic value of morphological and functional parameters on the MRE has a SE of $58.3 \%$ and SP of $100 \%$ if we want to confirm the diagnosis, and SE $87.5 \%$ and $\mathrm{SP}$ of $80 \%$ if we want to exclude the diagnosis. There was statistically significant correlation between the increased wall thickness and the accumulation of fat in the mesentery on MRE, and the gold standard (colonoscopy/histopathology, clinical presentation and laboratory findings).Correlation between results on US and MRE shows statistical significance in diagnostics of Crohn's disease in ileum, terminal ileum, Bauchini valve and cecum, ascendant colon in children. It showed high specificity (SP) for both diagnostic procedures in almost

Keywords:

Crohn disease,

child,

magnetic resonance imaging, ultrasound all segments (maximum value 94,7\%). Sensitivity (SE) varied from 0 to $83,3 \%$ in different bowel segments.

Conclusion: Our study showed that it is reliable to use MRE and US to exclude those who don't have Crohn's disease. Also, combination of morphological and functional parameters on MRE could be used in confirming and monitoring Crohn's disease. 
Cvejić S. et al. Ultrasound and Magnetic Resonance Enterography in diagnosis of Crohn's disease in children.

MedPodml 2018, 69(4):12-19

Ključne reči:

Kronova bolest,

deca,

magnetna rezonanca,

ultrazvuk

\section{Sažetak}

Uvod: Kronova bolest je hronična inflamatorna bolest creva, čiji tok karakterišu remisije i relapsi, a koja se najčešće javlja pre 30 . godine. Magnetno rezonantna enterografija (MRE) i ultrazvuk (UZ) preuzimaju glavnu ulogu od kolonoskopije i kompjuterizovane tomografije (CT) u dijagnostici, inicijalnoj proceni Kronove bolesti, praćenju njene aktivnosti i u detekciji i proceni komplikacija.

Cilj rada: Ispitati senzitivnost (SE), specifičnost (SP), pozitivnu prediktivnu vrednost (PPV), negativnu prediktivnu vrednost (NPV) UZ i MRE u dijagnostici Kronove bolesti, kao i ukupnu dijagnostičku vrednost MRE poređenjem morfoloških i funkcionalnih parametara sa nalazima ileokolonoskopije i patohistologije.

Materijal i metode: 40 pacijenata praćeno je od kraja 2009. do kraja 2016. godine. MRE i UZ su pregledani pacijenti upućeni zbog kliničkih i laboratorijskih nalaza, a koji su imali potvrđenu dijagnozu na endoskopiji/patohistologiji. UZ su evaluirani debljina zida creva, edem mezenterijuma (nagomilavanje masnog tkiva) i uvećanje mezenterijalnih limfnih čvorova. Pored ovih parametara, MRE su evaluirani i postkontrastno pojačanje intenziteta signala i znak ,stratifikacije”.

Rezultati: Sveukupna dijagnostička vrednost morfoloških i funkcionalnih parametara na MRE ima SE $58.3 \%$ i SP $100 \%$ u slučaju da potvrđujemo dijagnozu, i SE $87.5 \%$ i SP $80 \%$ u slučaju da isključujemo dijagnozu. Pokazana je statistički značajna korelacija između zadebljanja zida i nagomilavanja masnog tkiva u mezenterijumu na MRE, i zlatnog standarda (kolonoskopija/patohistološki nalaz, klinička slika i laboratorijske analize).

Korelacija UZ i MRE rezultata pokazuje visoku statističku značajnost u dijagnostici Kronove bolesti u ileumu, terminalnom ileumu, Bauhinievoj valvuli i cekumu, kao i u ascedentnom kolonu, u dečjoj populaciji. Pokazana je visoka SP obe dijagnostičke procedure u gotovo svim segmentima (maksimalno 94,7\%). SE se kretala od 0 do čak $83,3 \%$ u pojedinim delovima creva.

Zaključak: Naša studija je pokazala da je pouzdano koristiti MRE i UZ u otklanjanju sumnje na Kronovu bolest. Takođe, kombinacija funkcionalnih i morfoloških parametara na MRE pokazali su se korisnim u postavljanju dijagnoze Kronove bolesti i njenom praćenju.

\section{Uvod}

Kronova bolest je hronična inflamatorna bolest creva, progresivnog toka, sa najvećom incidencom javljanja između druge i četvrte decenije života (1), a čiji tok karakterišu remisije i relapsi $(2,3,4)$. Dijagnoza Kronove bolesti se postavlja na osnovu anamneze i fizikalnog pregleda, kao i laboratorijskih, endoskopskih i radioloških nalaza (5). U dijagnozi Kronove bolesti, posebno kod dece, neophodan je balans između preciznosti vizualizacionih metoda sa jedne strane, i neškodljivosti i lake izvodljivosti s druge strane. Kompjuterizovana tomografija ima visoku senzitivnost i specifičnost $u$ dijagnostici ove bolesti, ali je zbog štetnog jonizujućeg zračenja nepogodna za praćenje bolesti (6). Ileokolonoskopija omogućava rano otkrivanje bolesti posebno zbog detaljnog prikaza izgleda sluzokože i uzimanja uzoraka za biopsiju, te i dalje predstavlja zlatni standard u definitivnoj potvrdi ove bolesti. Sa druge strane, nepogodna je zbog slabije tolerancije pacijenata, zbog pripreme koju zahteva i neprijatnosti u toku pregleda (7). Sem toga, tanko crevo koje je često zahvaćeno, teško je dostupno ovoj vrsti pregleda (8). Magnetno rezonantna enterografija (MRE) je neinvazivna dijagnostička procedura koja ne izlaže pacijenta zračenju, i zbog mogućnosti primene velikog broja sekvenci, obezbeđuje prikaz ne samo intraluminalnih, već i ekstraluminalnih promena koje ka- rakterišu ovo oboljenje $(9,10)$. Pored toga što je neškodljiv i neinvazivan, ultrazvuk (UZ) ne zahteva od pacijenta pripremu pre pregleda, jeftiniji je od MRE i relativno se lako izvodi, te je našao svoju primenu u ovoj oblasti $(11,12)$.

Cilj našeg rada bio je da se ispita dijagnostička vrednost MRE poređenjem morfoloških i funkcionalnih parametara sa nalazima ileokolonoskopije i patohistologije, kao i da se ispita senzitivnost, specifičnost, pozitivna i negativna prediktivna vrednosti UZ i MRE u dijagnostici Kronove bolesti, korelacijom različitih parametara sa zlatnim standardom.

\section{Materijal i metode}

Studijom je obuhvaćeno 40 pacijenta kojima je na osnovu anamneze, kliničke slike (nespecifični bol u trbuhu, dijareja, gubitak težine, temperatura) i laboratorijskih nalaza (anemija, leukocitoza, hipoalbuminemija, povišeni zapaljenski markeri, prisustvo kalprotektina u stolici) postavljena sumnja na inflamatornu bolest creva. Pacijenti su ispitivani i lečeni u Univerzitetskoj Dečjoj Klinici (UDK) u periodu od kraja 2009. do kraja 2016. godine. Informacije su dobijene iz elektronske baze podataka UDK uz saglasnost etičkog komiteta matične ustanove.

Od ukupno 40 pacijenata, magnetnom rezonancom pregledano je 29 pacijenata (11 devojčica i 18 dečaka) 
Cvejić S. et al. Ultrasound and Magnetic Resonance Enterography in diagnosis of Crohn's disease in children.

MedPodml 2018, 69(4):12-19

koji su imali potvrđenu bolest na kolonoskopiji i/ili patohistologiji. Kod ovih pacijenata ispitivani su morfološki parametri (debljina zida creva, edem mezenterijuma-nagomilavanje masnog tkiva, mezenterijalna limfadenopatija) u T2W sekvencama, kao i funkcionalni parametri (postkontrastno pojačanje intenziteta signala i znak stratifikacije - povećanje intenziteta signala mukoze i seroze, dok je submukoza nižeg intenziteta) u dinamskim T1W postkontrastnim sekvencama. Kao zlatni standard koristili smo patohistološki nalaz i kolonoskopiju tokom koje su uzeti uzorci za PH.

U daljem radu, kod 26 pacijenata (12 dečaka i 14 devojčica) vršena je korelacija UZ i MRE nalaza. Kolonoskopijom i/ili patohistologijom (PH) je kod 23 pacijenta potvrđena Kronova bolest, kod 2 ulcerozni kolitis, a 1 pacijent je bio bez znakova bolesti. Najmlađi pacijent imao je 10, najstariji 20 godina, a prosek godina bio je 13.5 godina.

UZ i MRE snimali smo 8 segmenata creva: jejunum, ileum, Bauhinijeva valvula i cekum, ascedentni kolon, transverzum, descedentni i sigmoidni kolon. Ultrazvukom su evaluirani sledeći parametri: debljina zida zahvaćenog segmenta creva (patološkom je smatrana debljina zida $>3 \mathrm{~mm}$ ), edem mezenterijuma (nagomilavanje masnog tkiva) i uvećanje mezenterijalnih limfnih čvorova.

Kao zlatni standard za dokazivanje bolesti u jejunumu i ileumu koristili smo kliničku dijagnozu i laboratorijske analize (kalprotektin u stolici, CRP, sedimentacija), dok su za ostale delove creva to bili rezultati kolonoskopije sa ili bez patohistološke verifikacije. Prosečno vreme koje je proteklo između MRE/UZ i kolonoskopije/ $\mathrm{PH}$ bilo je 35 dana.

\section{Tehnika MRE i UZ pregleda}

Svi ispitanici su bili posebno pripremljeni za MR enterografiju. Priprema podrazumeva dijetalni režim ishrane 2 dana pre pregleda, a na sam dan izvođenja, $4 \mathrm{~h}$ pre pregleda pacijenti ne unose tečnost. Kao bifazično, intraluminalno kontrastno sredstvo koristili smo 2,5\% ma-

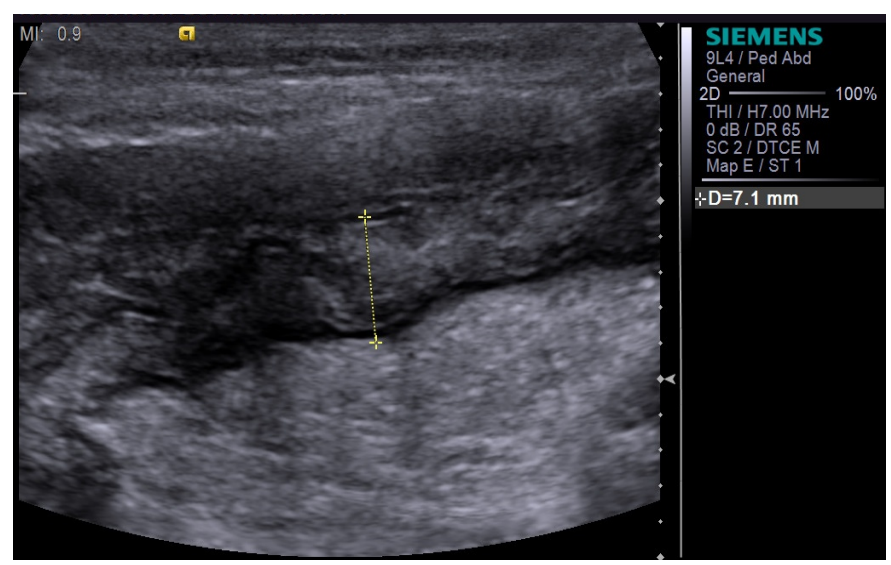

Slika 1. Dečak 13 godina, Kronova bolest; UZ prikaz zadebljanja terminalnog ileuma $7.1 \mathrm{~mm}$. nitol u zapremini od $1 \mathrm{~L}$, koji pacijent pije $1 \mathrm{~h}$ pre pregleda. Manitol se pokazao kao odlično kontrastno sredstvo, koje pokazuje u T2W povišen IS, a u T1W je hipointenzan. Pored toga ima izvrsnu moć distenzije lumena creva, što je i preduslov za adekvatnu procenu morfoloških promena zida creva, čime se izbegavaju lažno pozitivni rezultati.

MR enterografija je kod svih ispitanika izvedena na aparatu 1.5T (Achieva, Philips Healthcare, Best, The Nederlands), koristeći 16 kanalnu abdomen-torzo XL zavojnicu. Primenjen je standardni protokol za enterografiju, korišćenjem T2W (BTFE, SshTE sa i bez saturacije masti, biplanarno), kao i dinamskih postkontrastnih GRE (THRIVE) T1W nakon intravenske aplikacije paragadolinijumskog kontrastnog sredstva- $0,1 \mathrm{ml} / \mathrm{kg}$ TT.

Ultrazvučni pregled abdomena, sa posebnim osvrtom na creva, izveden je ili neposredno pre ili nakon MR enterografije. Optimalna popunjenost lumena creva manitolom omogućava distenziju lumena i bolji kontrast između intraluminalne tečnosti i zida creva. Svi ultrazvučni pregledi su izvedeni na aparatu S 2000 Siemens (Erlangen, Nemačka), primenom abdominalne konveksne multifrekventne sonde 3-6 MHz, kao i primenom linearne sonde 7-9 MHz. U svakom segmentu su evaluirani isti parametri kao i primenom MR enterografije (slika 1,2).

\section{Statistička analiza}

Statistička obrada podataka rađena je u SPSS 22 programu. Za analizu slaganja funkcionalnih i morfoloških parametara sa zlatnim standardom korišćen je kappa test. Pearson chi-square test koristili smo za analizu korelacije nalaza dobijenih pomoću UZ i MRE. Ispitana je statistička značajnost dobijenih korelacija $(\mathrm{p}<0,05$ smatra se statistički značajnom, a $\mathrm{p}<0,01$ statistički visoko značajnom).

Takođe, određene su senzitivnost, specifičnost, pozitivna i negativna prediktivna vrednost sa intervalima poverenja MRE kao dijagnostičke procedure u detekciji Kronove bolesti.

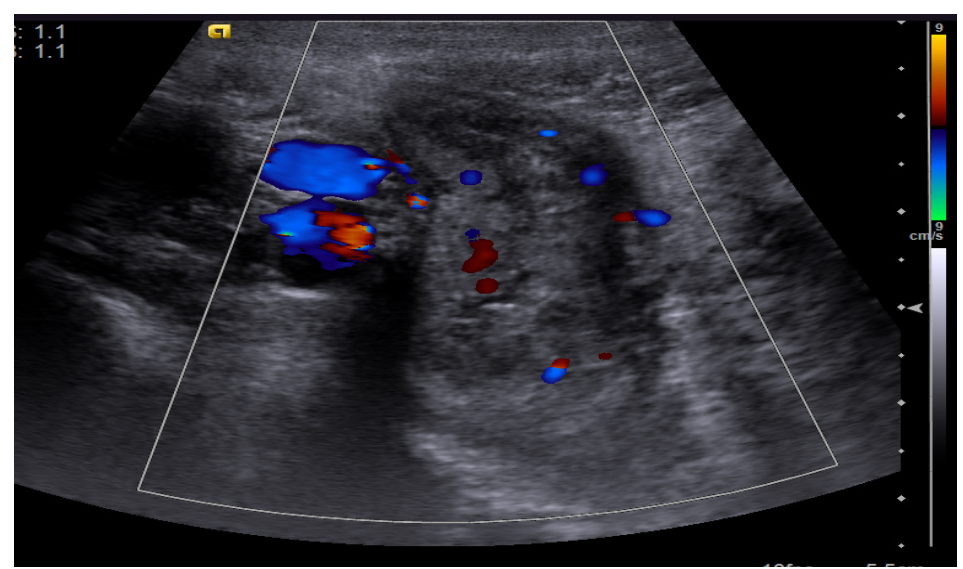

Slika 2. Pojačanje color doppler signala kao znak pojačane vaskularizacije usled inflamacije creva. 
Cvejić S. et al. Ultrasound and Magnetic Resonance Enterography in diagnosis of Crohn's disease in children.

\section{Rezultati}

Imali smo 29 pacijenata sa prethodno potvrđenom dijagnozom Kronove bolesti na kolonoskopiji/patohistologiji, koji su upućeni na MR od strane gastroenterologa. Za postavljanje dijagnoze Kronove bolesti magnetnom rezonancom, koristili smo 5 različitih morfoloških i funkcionalnih parametara: debljina zida creva (> 3mm smatrana je zadebljanjem), stratifikacija zida, postkontrastno pojačanje intenziteta signala zida creva, uvećanje mezenterijalnih limfnih žlezda i nagomilavanje masnog tkiva u mezenterijumu („fibrofatty proliferation").

Sveukupna dijagnostička vrednost morfoloških i funkcionalnih parametara na magnetnoj rezonanci

Sveukupnu dijagnostičku vrednost morfoloških i funkcionalnih parametara na magnetnoj rezonanci zasnovali smo na tome da najmanje 3 od 5 parametara budu pozitivni, kako bismo potvrdili dijagnozu, ili da svih 5 parametara budu negativni, kako bismo isključili dijagnozu. U prvom slučaju, postoji statistički značajna povezanost $(\mathrm{p}<0,05)$ sa zlatnim standardom, senzitivnost je $58.3 \%$, a specifičnost $100 \%$. U drugom slučaju, postoji statistički veoma značajna povezanost $(\mathrm{p}<0,01)$ sa zlatnim standardom, senzitivnost je $87,5 \%$, a specifičnost $80 \%$ (Tabela 1 ).

Poređenjem pojedinačnih MR parametara sa zlatnim standardom pokazana je statistički značajna korelacija između 2 parametra (zadebljanja zida i nagomilavanja masnog tkiva u mezenterijumu) i dijagnoze Kronove bolesti (Tabela 1).

Tabela 1. Morfološki i funkcionalni parametri posmatrani MR enterografijom - statistika acije usled inflamacije creva.

\begin{tabular}{|c|c|c|c|c|c|}
\hline & Kappa & SE\% (Interval poverenja) & SP \% (Interval poverenja) & PPV \% (IP) & NPV \% (IP) \\
\hline Debljina zida & $0,508^{* *}$ & $75(56,5-92)$ & $100(47,8-100)$ & $100(81,5-100)$ & $45,5(16,7-73,3)$ \\
\hline Postkontrastno pojačanje & 0,191 & $54,2(33,4-75)$ & $80(28,4-99,5)$ & $92,9(75-100)$ & $26,7(6,3-50)$ \\
\hline Fibrofatty proliferation & $0,290^{*}$ & $54,2(34,8-73,9)$ & $100(47,8-100)$ & $100(75,3-100)$ & $31,2(8,4-53,3)$ \\
\hline Grupa pozitivnih testova & $0,326^{\star}$ & $58,3(39,1-78,9)$ & $100(47,8-100)$ & $100(76,8-100)$ & $33,3(8,3-60)$ \\
\hline Grupa negativnih testova & $0.288^{\star *}$ & $87,5(72,7-100)$ & $80(28,4-99,5)$ & $95,5(85,7-100)$ & $57,1(20-100)$ \\
\hline
\end{tabular}

${ }^{*} \mathrm{p}<0,05,{ }^{*} \mathrm{p}<0,01$, Kappa vrednost ( 0 - nema saglasnosti između ispitivanih parametara osim slučajne; $0,01-0,20$ - slaba saglasnost; 0,21 0,40 - dobra saglasnost; 0,41-0,60 - vrlo dobra saglasnost; 0,61-0,80 - odlična saglasnost; 0.81 -1 - skoro savršsena saglasnost)

\section{Korelacija nalaza na UZ i MRE}

U tabeli 1 prikazan je broj zahvaćenih segmenata analiziranih MRE i UZ. Od ukupno 208 analiziranih segmenata creva, MRE je kod 41 pokazala pozitivan nalaz, a UZ kod 66. Pozitivnim na pregledu najviše puta bili su zahvaćeni ileum, terminalni ileum i Bauhini i cekum, kako na MRE, tako i na UZ.

Korelacija UZ i MRE rezultata pokazuje visoku statističku značajnost u ileumu, terminalnom ileumu, Bauhinievoj valvuli i cekumu, kao i u ascedentnom kolonu (tabela 2).
Zadebljanje zida

Zadebljanje zida uočeno je kod 18 od 29 pacijenata. Prosečna maksimalna debljina zida bila je $7.78 \mathrm{~mm}$ (interval $4-13 \mathrm{~mm}$ ). Povezanost prosečne maksimalne debljine zida merene na MR sa dijagnozom na zlatnom standardu pokazala se veoma statistički značajnom ( $\mathrm{p}<$ 0,01 ). Debljina zida $3 \mathrm{~mm}$ ili veća ima senzitivnost $75 \%$ i specifičnost $100 \%$ za potvrdu Kronove bolesti (Tabela 1).

Nagomilavanje masnog tkiva u mezenterijumu („fibrofatty proliferation“)

Trinaest od dvadeset i devet pacijenata imalo je nagomilavanje masnog tkiva u mezenterijumu (Tabela $\mathbf{1}$ ), čija se povezanost sa dijagnozom na zlatnom standardu pokazala statistički značajnom ( $\mathrm{p}<0,05)$. Nagomilavanje masnog tkiva u mezenterijumu ima senzitivnost $54,2 \%$ i specifičnost $100 \%$ za potvrdu Kronove bolesti (Tabela 1).

\section{Ostale promene}

Posmatrajući pojedinačno stratifikaciju zida, uvećanje mezenterijalnih limfnih žlezda i postkontrastno pojačanje intenziteta signala zida creva na MRE, nije nađena statistički značajna korelacija između potvrde dijagnoze Kronove bolesti pomoću ovih parametara na MRE i zlatnog standarda (Tabela $\mathbf{1}$ ). 
Cvejić S. et al. Ultrasound and Magnetic Resonance Enterography in diagnosis of Crohn's disease in children.

MedPodml 2018, 69(4):12-19

$(35,7 \%)$. Sa druge strane senzitivnost je pokazala vrlo varijabilne vrednosti, od $0 \mathrm{u}$ ascedentnom i descedentnom kolonu na MRE do čak 83,3 \% u terminalnom ileumu i $81,8 \%$ u Bauhinijevoj valvuli i cekumu na UZ. Izračunavanjem aritmetičke sredine na osnovu SE i SP iz svih delova creva, došli smo do podatka da je sveukupna SE bila 38,6\% za MRE i 49 \% za UZ, a SP je bila $91 \%$ za MRE i 73,3\% za UZ. U dijagnostici promena na Bauhinijevoj valvuli i cekumu kao i u sigmoidnom kolonu, zapaža se povećanje senzitivnosti u slučaju kada su primenjene obe procedure kao upareni testovi, u odnosu na korišćenje UZ i MRE pojedinačno.
Tabela 2. Jačina korelacije nalaza na MRE i UZ.

\begin{tabular}{ll} 
Deo creva & Kappa \\
\hline Jejunum & 0,245 \\
Ileum & $0,606^{* *}$ \\
Term. ileum & $0,538^{* *}$ \\
Bauhini i cekum & $0,474^{* *}$ \\
Ascedentni kolon & $0,468^{\star *}$ \\
Transverzum & $/$ \\
Descedentni kolon & $-0,054$ \\
Sigma & 0,284 \\
\hline Kappa $(0,01-0,2$ slaba saglasnost, $0,21-0,4$ dobra, $0,41-$ \\
0,6 vrlo dobra, $0,61-0,8$ odlična i $0,81-1$ skoro savršena); \\
${ }^{*} \mathrm{p}<0,05,{ }^{* *} \mathrm{p}<0,01$.
\end{tabular}

Tabela 3. Senzitivnost (SE), specifičnost (SP), pozitivna prediktivna vrednost (PPV), negativna prediktivna vrednost (NPV) svih segmenata creva snimanih UZ, MRE ili parom dijagnostičkih metoda.

\begin{tabular}{|c|c|c|c|c|c|c|}
\hline Deo creva & Dijagnostika & Kappa & SE \% (IP) & SP \% (IP) & PPV \% (IP) & NPV \% (IP) \\
\hline \multirow{3}{*}{ Jejunum } & MRE & 0,245 & $36,4(10-70)$ & $86,7(66,7-100)$ & $66,7(22,3-95,7)$ & $65(42,1-85)$ \\
\hline & $\mathrm{UZ}$ & $0,302^{*}$ & $27,3(0-55,6)$ & 100 (const.) & $100(229,2-100)$ & $65,2(45,5-83,3)$ \\
\hline & par & 0,245 & $36,4(9,-66,7)$ & $86,7(69,2-100)$ & $66,7(22,2-95,7)$ & $65(45-85)$ \\
\hline \multirow{3}{*}{ Ileum } & MRE & $0,591^{\star}$ & $63,6(30-90)$ & $93,3(76,9-100)$ & $87,5(60-100)$ & $77,8(55,6-94,7)$ \\
\hline & $\mathrm{UZ}$ & $0,339^{\star}$ & $81,8(57,1-100)$ & $60(31,3-84,6)$ & $60(33,3-85,7)$ & $81,8(57,1-100)$ \\
\hline & par & $0,331 \sim$ & $81,8(57,1-100)$ & $53,3(26,7-78)$ & $56,2(33,3-80)$ & $80(50-100)$ \\
\hline \multirow{3}{*}{ Terminalni ileum } & MRE & $0,462^{\star}$ & $75(45,5-100)$ & $71,4(45,5-93)$ & $69,2(43,8-92,3)$ & $76,9(53,3-100)$ \\
\hline & $\mathrm{UZ}$ & 0,183 & $83,3(58,3-100)$ & $35,7(8,4-63,6)$ & $52,6(29,4-76,5)$ & $71,4(33,3-100)$ \\
\hline & par & 0,183 & $83,3(58,3-100)$ & $35,7(8,4-69,6)$ & $52,6(31,3-76,2)$ & $71,4(33,3-100)$ \\
\hline \multirow{3}{*}{ Bauhini i cekum } & MRE & $0,606^{\star *}$ & $66,7(40-92,3)$ & $92,9(75-100)$ & $88,9(60,1-100)$ & $76,5(55,6-94,7)$ \\
\hline & $\mathrm{UZ}$ & $0,388^{\star}$ & $75(50-100)$ & $64,3(36,4-89)$ & $64,3(38,5-87,5)$ & $75(50-100)$ \\
\hline & par & $0,468^{*}$ & $83,3(60-100)$ & $64,3(36,4-89)$ & $66,7(41,7-90,9)$ & $81,8(58,3-100)$ \\
\hline \multirow{3}{*}{ Ascedentni kolon } & MRE & $-0,073$ & $0(/)$ & $94,4(82,4-100)$ & $0(/)$ & $68(50-84,6)$ \\
\hline & $\mathrm{UZ}$ & 0,235 & $25(0-60)$ & $94,4(82,4-100)$ & $66,7(13,5-100)$ & $73,9(54,3-91,3)$ \\
\hline & par & 0,235 & $25(0-60)$ & $94,4(82,4-100)$ & $66,7(13,5-100)$ & $73,9(55-90,9)$ \\
\hline \multirow{3}{*}{ Transverzum } & MRE & 1 & const. & $100(85,4-100)$ & const. & $73,1(53,8-88,5)$ \\
\hline & $\mathrm{UZ}$ & $0,661^{\star *}$ & $57,1(16,7-100)$ & $100(47,9-100)$ & $100(47,3-100)$ & $86,4(70,8-100)$ \\
\hline & par & $0,661^{\star *}$ & $57,1(16,7-100)$ & $100(47,3-100)$ & $100(47,3-100)$ & $86,4(70,8-100)$ \\
\hline \multirow{3}{*}{ Descedentni kolon } & MRE & $-0,072$ & $0(/)$ & $94,7(82,4-100)$ & $0(/)$ & $72(54,3-88)$ \\
\hline & $\mathrm{UZ}$ & 0,117 & $14,3(0-50)$ & $94,7(8,8-100)$ & $50(2,5-100)$ & $75(58,3-90,9)$ \\
\hline & par & 0,046 & $14,3(0-50)$ & $89,5(73,3-100)$ & $33,3(1,7-100)$ & $73,9(56,5-90,5)$ \\
\hline \multirow{3}{*}{ Sigma } & MRE & 0,284 & $28,6(0-71,4)$ & $94,7(82,4-100)$ & $66,7(13,5-100)$ & $78,3(59,1-92,3)$ \\
\hline & $\mathrm{UZ}$ & 0,284 & $28,6(0-66,7)$ & $94,7(82,4-100)$ & $66,7(13,5-100)$ & $78,3(58,3-95,2)$ \\
\hline & par & $0,355 \sim$ & $42,9(0-87,5)$ & $89,5(75-100)$ & $60(18,9-100)$ & $81(63,6-95,5)$ \\
\hline
\end{tabular}

IP (interval poverenja); ${ }^{\star} \mathrm{p}<0,05,{ }^{\star *} \mathrm{p}<0,01, \sim$ znači da bi $\mathrm{p}$ bilo $<0,05$ da je veći uzorak.

\section{Diskusija}

MRE postaje vodeća alternativa kada je endoskopp ija nekompletna, kontraindikovana ili odbijena od strane pacijenta. Trenutno, najvažnija uloga MRE je potvrđivanje dijagnoze bolesti, kao i praćenje pacijenata sa već potvrđenom dijagnozom (13). U poslednjih desetak godina UZ je prihvaćen kao inicijalna dijagnostika za rano detektovanje i praćenje bolesti, pre svega zbog dostupnosti i niske cene (14), ali i zbog rastuće senzitivnosti i specifičnosti.
Schreyer i saradnici poredili su MRE sa konvencionalnom endoskopijom, koristeći zadebljanje zida i postkontrastno pojačanje intenziteta signala zida creva kao pokazatelje inflamacije na MRE (15). U njihovoj studiji, MRE je pokazala senzitivnost i specifičnost 31,6\% i $100 \%$. Ovi nalazi su u skladu sa ranijom studijom Koha i saradnika (16), koji su poredili nalaz na MRE sa endoskopijom ili operativnim nalazom, i dobili senzitivnost $59 \%$. Slično tome, naši rezultati pokazuju senzitivnost i specifičnost 
Cvejić S. et al. Ultrasound and Magnetic Resonance Enterography in diagnosis of Crohn's disease in children.

MedPodml 2018, 69(4):12-19

$58,3 \%$ i $100 \%$, u slučaju da su bilo koja 3 od 5 morfoloških i funkcionalnih parametara bili pozitivni na MRE.

Normalne debljine zida tankog creva i kolona su 1-2 $\mathrm{mm}$ i $3 \mathrm{~mm}$ u proseku, kada je lumen distendiran (1720). Svaki deo creva čija je debljina veća od $3 \mathrm{~mm}$, smatra se patološkim $(21,22)$. Naši rezultati pokazali su da se zadebljanje zida creva veće od $3 \mathrm{~mm}$ može koristiti kao parametar za postavljanje dijagnoze Kronove bolesti (slika 3). Saglasno sa našim rezultatima, Shoenut i saradnici (23) našli su statistički značajnu korelaciju između težine bolesti na endoskopiji i zadebljanja zida na MRE.

Koh i saradnici (16) pokazali su da aktivna inflamacija dovodi do hiperemije zida creva, tako da nakon davanja kontrastnog sredstva zahvaćeni segmenti creva imaju viši intenzitet signala u odnosu na zdrave delove creva. Daljom analizom pokazano je da pojačanje intenziteta signala zida creva može biti homogeno, ali da se često viđa i slojevit izgled inflamiranog zida (stratifikacija zida) $(24,25)$. Stratifikacija zida creva označava povećanje intenziteta signala mukoze i seroze, dok je submukoza nižeg intenziteta. Objašnjenje leži u činjenici da je akutna inflamacija često povezana sa edemom submukoze, koja se zbog toga ne opacifikuje nakon davanja kontrasta $(24,25)$, što najčešće ukazuje na početak Kronove bolesti. U daljem toku, dolazi do razvoja fibroze u submukozi, a svaka nova akutizacija dovodi do homogenog pojačanja intenziteta signala zida creva (16). U našem istraživanju nije pokazana statistički značajna korelacija između postkontrastnog pojačanja i zlatnog standarda, kao ni stratifikacije zida i zlatnog standarda, što se može objasniti činjenicom da je većina pacijenata uključenih u istraživanje imala dugotrajnu Kronovu bolest sa većim brojem akutizacija i posledičnim razvojem fibroze u submukozi zida creva, kao i činjenicom da je deo ispitanika bio u remisiji ili pod terapijom.

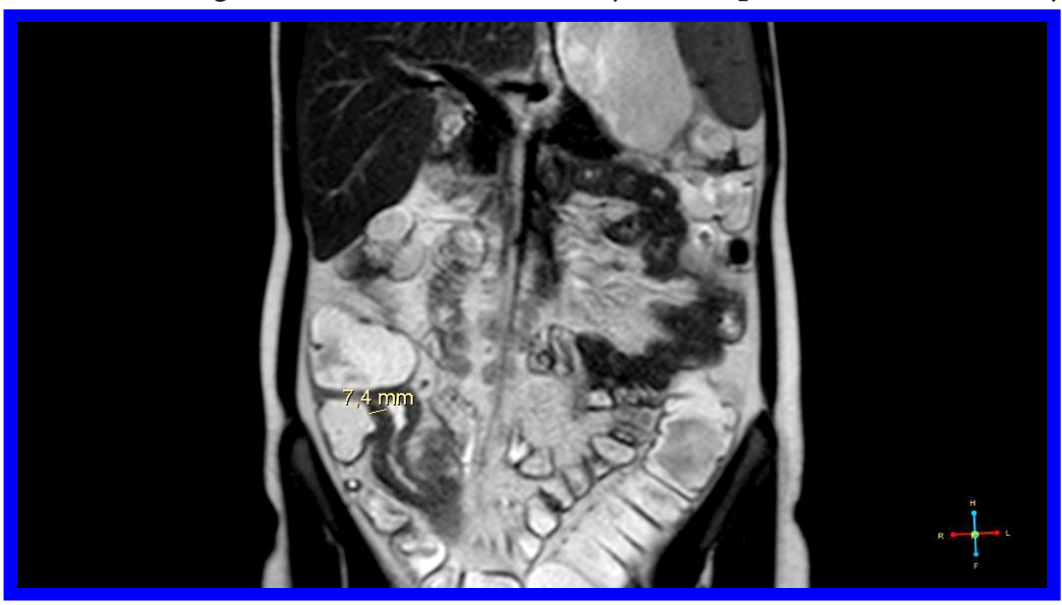

Slika 3. Zadebljanje zida distalnog ileuma kod pacijenta sa Kronovom bolešću

Prednost MR u odnosu na endoskopiju je sposobnost identifikacije perienteričnih promena (26), kao što su nagomilavanje masnog tkiva u mezenterijumu (slika 4) i uvećanje limfnih žlezda (slika 5). U akutnoj bolesti, promene u perienteričnom masnom tkivu nastaju usled edema i inflamacije. U hroničnoj fazi, dolazi do razvoja fibroze i proliferacije masnog tkiva kao posledice zalečenja. Rimola i saradnici (27) našli su statistički značajnu

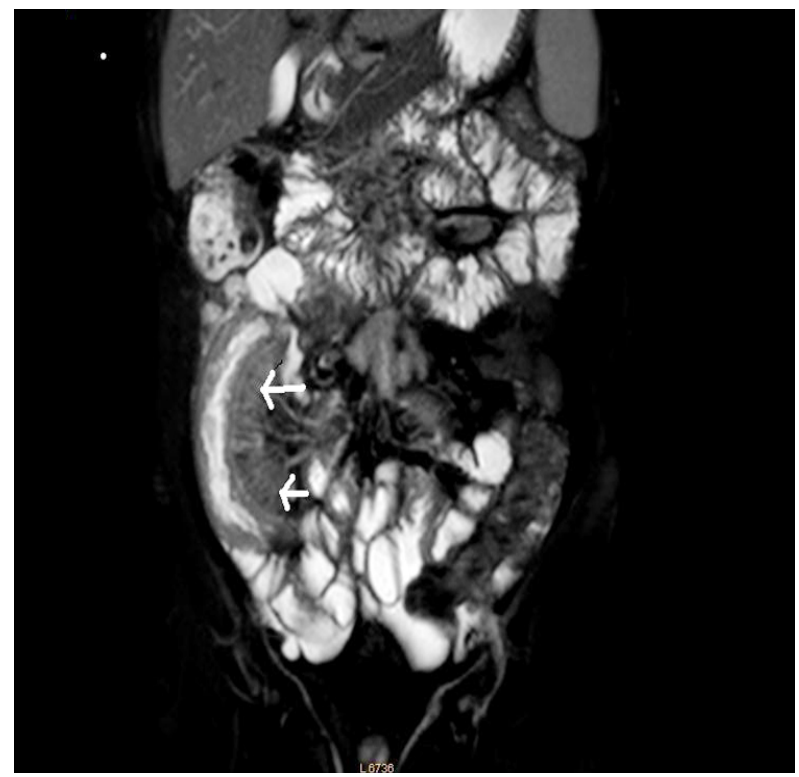

Slika 4. Promene u perienteričnom masnom tkivu kod pacijenta sa Kronovom bolešću - "fibrofatty proliferation" korelaciju između endoskopskih nalaza i promena u mezenteričnom masnom tkivu, što je u saglasnosti sa našim rezultatima.

Mada su dosadašnja istraživanja ukazala na značaj perienterične limfadenopatije u dijagnostici Kronove bolesti (24), mi nismo dobili statistički značajnu korelaciju sa zlatnim standardom.

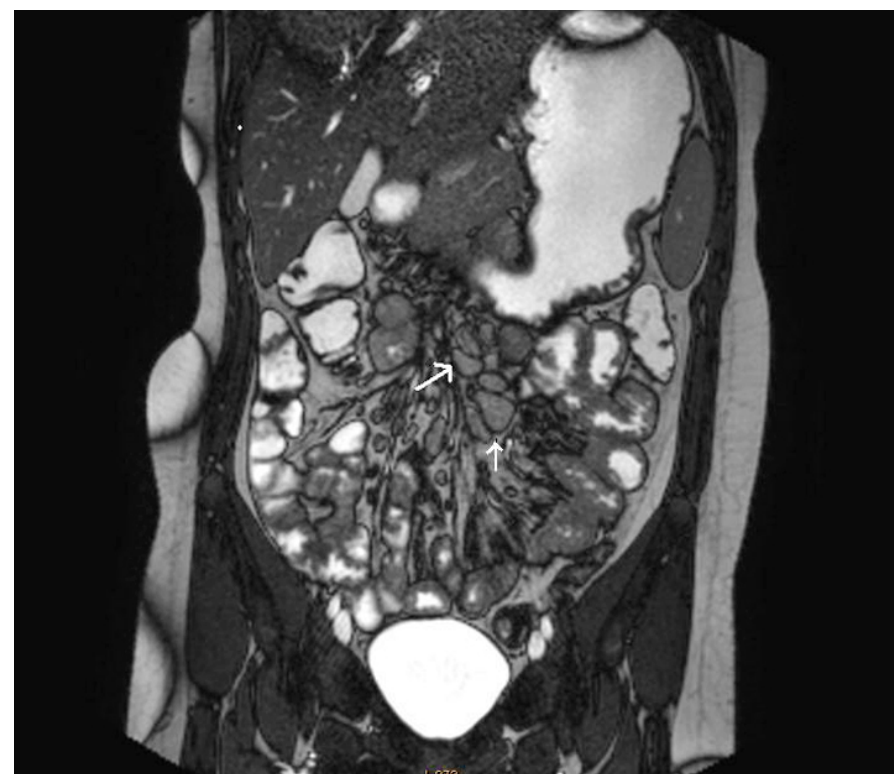

Slika 5. Mezenterijalna limfadenopatija kod pacijenta sa Kronovom bolešću 
Cvejić S. et al. Ultrasound and Magnetic Resonance Enterography in diagnosis of Crohn's disease in children.

MedPodml 2018, 69(4):12-19

Uzimajući u obzir vrednosti dobijene poređenjem nalaza na MRE sa zlatnim standardom za svaki pojedinačni deo creva, prosečna vrednost specifičnosti MRE je 91\% i značajno je viša od $75 \%$ koje su publikovali Koh i sar. (16). Iako je vrednost specifičnosti niža od naših rezultata, Koh i saradnici su u ovoj studiji dokumentovali vrlo visoku vrednost senzitivnosti (92\%) koja je kod nas iznosi svega 38,6\%. Drugim rečima, naša studija ukazuje da primenom MRE, sa velikom verovatnoćom isključujemo postojanje inflamatorne bolesti creva, a sa druge strane, niske vrednosti senzitivnosti ukazuju na smanjenu mogućnost postavljanja dijagnoze bolesti (pogotovo u jejunumu). Objašnjenje ovako niske vrednosti senzitivnosti su rezultati dobijeni na ascedentnom i descedentnom kolonu gde je samo po jedna osoba imala patološke promene. Slična je situacija sa transverzalnim segmentom kolona gde ni kod jednog od naših ispitanika nije postojao patološki nalaz što je rezultovalo veoma malim brojem stvarno pozitivnih rezultata.

UZ je pokazao SE od 49 \% koja je relativno slična vrednosti od $55 \%$ koju su dobili Ziech i sar.(28). Vrednost SP ove metode u našem istraživanju od $73,7 \%$ pokazala se kao manja u poređenju sa $100 \%$ koja je dokazana u radu Pallotta i sar.(29). Treba imati u vidu da razlike u SE i SP zavise od parametara koje smo koristili za procenu, granične vrednosti debljine zida, kao i od kvaliteta same UZ opreme (30). Takođe, treba istaći da mogu da nastanu lažno pozitivni (LP) i lažno negativni (LN) rezultati zbog toga što zadebljanje zida creva može da se javi i kod drugih inflamatornih, neoplastičnih i infektivnih bolesti (31). Ipak, pokazano je da kada se koristi kontrastni UZ, u stanju je da prikaže lezije sa SE od 95 \% (32).

Korišćenjem para testova, tj. kombinovanjem UZ i MRE dobijena ukupna SE od $53 \%$ što je veće od pojedinačnih SE koje su iznosile 38,6 \% na MRE i 49 \% na UZ. Međutim, ukupna SP para testova od 76,6 \% je manja od
$91 \%$ koju MRE postiže kada se koristi sam. Ovakvi rezultati govore da bi kombinovanjem testova mogla da se poboljša detekcija onih koji su stvarno bolesni.

Posmatrajući redom delove creva zapažamo da su $\mathrm{u}$ jejunumu i kolonu zabeležene dosta niže vrednosti SE u poređenju sa ostalim delovima creva (tabela 3 ). U literaturi su dobro poznata ograničenja u otkrivanju bolesti u jejunumu i ileumu zbog nedovoljne distenzije lumena (33). Takođe, zbog teške eksploracije jejunuma endoskopijom, klinički i laboratorijski nalazi predstavljali su zlatni standard za procenu nalaza na MRE što je dovelo do loših rezultata usled male dijagnostičke vrednosti tih parametara.

Ograničenja naše studije su većinom u vezi sa njenom retrospektivnom prirodom: naš uzorak je nehomogen, usled različitih dužina trajanja bolesti i lečenja. Takođe, vremenski period protekao između MRE, UZ i zlatnog standard mogao je uticati na neslaganje rezultata. Još jedno od ograničenja naše studije je relativno mali broj pacijenata.

\section{Zaključak}

Zadebljanje zida creva veće od $3 \mathrm{~mm}$ i nagomilavanje masnog tkiva u mezenterijumu na MRE mogli bi se koristiti kao pokazatelji bolesti. Nepostojanje morfoloških i funkcionalih parametara na MRu sa visokom senzitivnošću i specifičnošću (87,5 \% i 80 \%) isključuje dijagnozu Kronove bolesti.

MRE i UZ pokazuju visoku međusobnu povezanost i sa SP od $91 \%$ i 73,7 \% obezbeđuju visoku pouzdanost u označavanju pacijenata kao zdravih. Dalja istraživanja u ovom pravcu mogla bi da pokažu što veću bezbednost za korišćenje kombinacije ova dva testa umesto nekih invazivnih metoda ili aparata koji emituju zračenje, u cilju postavljanja dijagnoze Kronove bolesti.

\section{Literatura}

1. Loftus EV Jr, Schoenfeld P, Sandborn WJ. The epidemiology and natural history of Crohn's diseasein population-based patient cohorts from NorthAmerica: a systematic review. Aliment Pharmacol Ther 2002; 16:51-60.

2. Cosnes, J. et al. Epidemiology and natural history of inflammatory bowel diseases. Gastroenterology 2012; 140:17851794.

3. Loftus, EV Jr. Clinical epidemiology of inflammatory bowel disease: incidence, prevalence, and environmental influences. Gastroenterology 2004; 126:1504-1517.

4. Abraham, C. \& Cho, J.H. Inflammatory bowel disease. N. Engl. J. Med. 2009; 361:2066- 2078.

5. Kichul Yoon, Kyu-Tae Chang, and Hong J. Lee, Review Article MRI for Crohn's Disease: Present and Future. BioMed Research International 2015; 786802.

6. Panes J, Bouzas R, Chaparro M, Garcia-Sanchez V, Gisbert JP, Martinez de GB, et al. Systematic review: the use of ultrasonography, computed tomography and magnetic resonance imaging for the diagnosis, assessment of activity and abdominal complications of Crohn's disease. Aliment Pharmacol Ther 2011; 34(2):125-45.
7. Florie J, Horsthuis K, Hommes DW, Nio CY, Reitsma JB, van Deventer SJ, et al. Magnetic resonance imaging compared with ileocolonoscopy in evaluating disease severity in Crohn's disease. Clin Gastroenterol Hepatol 2005; 3:12211228.

8. Leyendecker J, Bloomfeld R, DiSantis J, Waters G, Mott R, Bechtold R. MR enterigraphy in the management of patients with Crohn disease. Radio Graphics 2009; 29:18271846.

9. Sauer CG, Middleton JP, Alazraki A, Udayasankar UK, Kalb $\mathrm{B}$, Applegate KE, et al. Comparison of magnetic resonance enterography with endoscopy, histopathology, and laboratory evaluation in pediatric Crohn disease. J Pediatr Gastroenterol Nutr 2012; 55:178-184.

10. Golder SK, Schreyer AG, Endlicher E, Feuerbach S, Scholmerich J, Kullmann F, et al. Comparison of capsule endoscopy and magnetic resonance (MR) enteroclysis in suspected small boweldisease. Int J Colorectal Dis 2006; 21:97-107.

11. Ahmad T, Greer ML, Walters T, Navarro O. Bowel sonography and MR enterography in children. AJR Am J Roentgenol 2016; 206(1):173-81. 
Cvejić S. et al. Ultrasound and Magnetic Resonance Enterography in diagnosis of Crohn's disease in children.

MedPodml 2018, 69(4):12-19

12. Stuart S, Conner T, Ahmed A, Steward M, Maclachlan J, Wylie P, Beal I. The smaller bowel: imaging the small bowel in paediatric Crohn's disease. Postgrad Med J 2011; 87: 288297.

13. Casciani E, De Vincentiis C, Polettini E, Masselli G et al. Imaging of the small bowel: Crohn's disease in paediatric patients, World J Radiol 2014; 6:313-328.

14. Poza-Cordón J, Ripollés-González T. Utility of abdominal ultrasonography in the diagnosis and monitoring of inflammatory bowel disease. Rev Esp Enferm Dig 2014; 106:395408.

15. Schreyer AG, Rath HC, Kikinis R, et al. Comparison of magnetic resonance imaging colonoscopy for the assessment of intestinal inflammation in patients with inflammatory bowel disease: a feasibility study. Gut 2005; 54:250-6.

16. Koh DM, Miao Y, et al. MR Imaging Evaluation of the Activity of Crohn's Disease. AJR Am J Roentgenol 2001; 6:132532.

17. Gourtsoyiannis N, Papanikolaou N, Grammatikakis J, Prassopoulos P. MR enteroclysis: technical considerations and clinical applications. Eur Radiol 2002; 12:2651-2658.

18. Desai RK, Tagliabue JR, Wegryn SA, et al. CT evaluation of wall thickening in the alimentary tract. RadioGraphics 1991; 11:771-783.

19. Balthazar EJ. CT of the gastrointestinal tract: principles and interpretation. AJR Am J Roentgenol 1991; 156:23-32.

20. Macari M, Balthazar EJ. CT of bowel wall thickening: significance and pitfalls of interpretation. AJR Am J Roentgenol 2001; 176:1105-1116.

21. Low RN, Sebrechts CP, Politoske DA, et al. Crohn disease with endoscopic correlation: singleshot fast spin-echo and gadolinium-enhanced fatsuppressedspoiled gradient-echo MR imaging. Radiology 2002; 222:652-660.

22. Turetschek K, Schober E, Wunderbaldinger P, et al. Findings at helical CT-enteroclysis in symptomatic patients with Crohn's disease: correlation with endoscopic and surgical findings. J Comput Assist Tomogr 2002; 26:488-492.

23. Shoenut JP, Semelka RC, Silverman R, Yaffe CS, Micflikier AB. Magnetic resonance imaging in inflammatory bowel disease. J Clin Gastroenterol 1993; 17:73-78.

24. Gourtsoyiannis N, Papanikolaou N, Grammatikakis J, Papamastorakis G, Prassopoulos P, Roussomoustakaki M. Assessment of Crohn's disease activity in the small bowel with $\mathrm{MR}$ and conventional enteroclysis: preliminary results. European Radiology 2004. 14:1017-1024.

25. Dušan Vukićević, Marko Svetel, Nataša Stanković, Jelena Kovač MR enterokliza u evaluaciji i praćenju pacijenata sa Kronovom bolešću, Medicinski podmladak 2014.

26. Furukawa A, Saotome T, Yamasaki M, et al. Crosssectional imaging in Crohn disease. RadioGraphics 2004; 24:689702.

27. J. Rimola, S. Rodriguez, O. Garcia-Bosch et al., Magnetic resonance for assessment of disease activity and severity in ileocolonic Crohn's disease, Gut 2009; 58:1113-1120.

28. Ziech ML, Hummel TZ, Smets AM, Nievelstein RA, Lavini C, Caan MW, et al, Accuracy of abdominal ultrasound and MRI for detection of Crohn's disease and ulcerative colitis in children. Pediatr Radiol. 2014; 44:1370-1378.

29. Pallotta N, Tomei E, Viscido A, Calabrese E, Marcheggiano A, Caprilli R, et al., Small intestine contrast ultrasonography: an alternative to radiology in the assessment of small bowel disease. Inflamm Bowel Dis 2005; 11: 146-153.

30. Nylund K, Hausken T, Gilja OH. Ultrasound and inflammatory bowel disease. Ultrasound Q 2010; 26:3-15.

31. Truong M, Atri M, Bret PM, Reinhold C, Kintzen G, Thibodeau M, et al. Sonographic appearance of benign and malignant conditions of the colon. AJR Am J Roentgenol 1998; 170:1451-5.

32. Kumar S, Hakim A, Alexakis C, Chhaya V, Tzias D, Pilcher $J$, et al. Small intestinal contrast ultrasonography for the detection of small bowel complications in Crohn's disease: correlation with intraoperative findings and magnetic resonance enterography. J Gastroenterol Hepatol 2015; 30:8691.

33. Darge K, Anupindi S, Keener H, Rompel O. Ultrasound of the bowel in children: how we do it. Pediatr Radiol 2010; 40:528-536. 